\title{
Effects of meat consumption and vegetarian diet on risk of wrist fracture over 25 years in a cohort of peri- and postmenopausal
} women

\author{
Donna L Thorpe ${ }^{1, *}$, Synnove F Knutsen ${ }^{2}$, W Lawrence Beeson ${ }^{2}$, Sujatha Rajaram ${ }^{3}$ \\ and Gary E Fraser ${ }^{2}$ \\ 'Department of Physical Therapy, School of Allied Health Professions, Loma Linda University, Loma Linda, CA \\ 92350, USA: ${ }^{2}$ Department of Epidemiology and Biostatistics, School of Public Health, Loma Linda University, \\ Loma Linda, CA, USA: ${ }^{3}$ Department of Nutrition, School of Public Health, Loma Linda University, Loma Linda, \\ CA, USA
}

Submitted 6 February 2006: Accepted 5 June 2007: First published online 9 August 2007

\begin{abstract}
Background: Evidence suggesting that a diet high in fruits and vegetables may be beneficial to bone health has sparked interest in the potential benefit of a vegetarian diet. However, other studies have raised a question regarding the adequacy of protein in such a diet.

Objective: The aim of the present study was to take a whole foods approach in examining the effects of foods high in protein on the risk of wrist fracture (WF) in a cohort with a significant proportion consuming a meat-free diet.

Design: A cohort study of women who completed two lifestyle surveys 25 years apart.

Subjects: One thousand eight hundred and sixty-five peri- and postmenopausal women at the time of the first survey.

Results: There was a significant interaction between meat consumption and foods high in vegetable protein. Among vegetarians, those who consumed the least vegetable protein intake were at highest risk for fracture. However, increasing levels of plant-based high-protein foods decreased WF risk, with a $68 \%$ reduction in risk (hazard ratio $(\mathrm{HR})=0.32,95 \%$ confidence interval $(\mathrm{CI}) 0.13-0.79$ ) in the highest intake group. Among those with lowest vegetable protein consumption, increasing meat intake decreased the risk of WF, with the highest consumption decreasing risk by $80 \%$ ( $\mathrm{HR}=0.20$, 95\% CI 0.06-0.66).

Conclusions: The finding that higher consumption frequencies of foods rich in protein were associated with reduced WF supports the importance of adequate protein for bone health. The similarity in risk reduction by vegetable protein foods compared with meat intake suggests that adequate protein intake is attainable in a vegetarian diet.
\end{abstract}

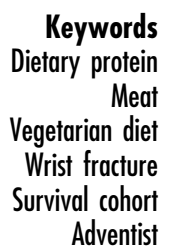

Wrist fracture (WF) is the most commonly occurring fracture in women under 75 years of age in the USA and northern Europe ${ }^{1}$. The estimated lifetime risk of WF in women is $16 \%$. Interestingly, this type of fracture occurs typically in women who are in good health and active, often reporting that they walk briskly ${ }^{1}$. Although the medical sequelae and economic burden of WF are not as serious as for hip fracture, the occurrence of WF is associated with increased risk of a subsequent fracture at the hip in both men and women ${ }^{2}$. Thus there is an increasing interest in identifying modifiable risk factors, as demonstrated by the growing number of studies on WF over the past 15 years ${ }^{1,3-9}$.
The potential for diet to protect against low-energy fractures has been investigated for more than 40 years ${ }^{10}$. Most of the attention in research and public health efforts has been directed towards the role of calcium, dairy foods and vitamin D in bone health. More recently recommendations to consume a diet rich in fruits and vegetables as a preventive measure against risk of low-energy fractures has been given with increasing frequency in reviews of diet and bone health ${ }^{11,12}$. Fruits and vegetables are key dietary sources of magnesium, potassium, vitamin $\mathrm{C}$, vitamin $\mathrm{K}$ and folate, adequate quantities of which have been associated with higher bone mineral density (BMD), decreased bone loss with ageing or reduced risk 
of fracture ${ }^{12,13}$. Protein ${ }^{8,14}$, total fat ${ }^{15}$, monounsaturated fat $^{16}$, polyunsaturated fatty acids ${ }^{17}$, phyto-oestrogens ${ }^{18}$, vitamin $\mathrm{A}^{19}$ and vitamin $\mathrm{B}_{12}{ }^{20}$ have also been implicated as factors affecting risk of osteoporosis and fragility fractures.

Along with the health promotional message regarding the importance of fruits and vegetables in the diet, there is an increasing interest in the potential benefits of a vegetarian diet for bone health. However, little is known about the effects of vegetarian diets on risk of a low-energy fracture of any kind. Because a number of studies have observed that vegetarians consume a diet lower in protein than omnivores ${ }^{21-23}$, some have been concerned that a vegetarian diet may not provide an adequate intake of protein for bone health. Thus the focus of the present study was to examine the effects of foods high in protein and the effect of an absence of meat in the diet relative to low-energy WF. The study participants were peri- and postmenopausal women in a cohort of white female Seventh-day Adventists (SDAs) who completed two lifestyle questionnaires, the first of which was administered in 1976 and the second being initiated in 2002.

\section{Methods and materials}

\section{Adventist Healtb Study 1 (1976-1988)}

The first Adventist Health Study (AHS-1) was a prospective cohort study designed to examine the risk of cancer, coronary heart disease and mortality among nonHispanic white SDAs, a population that encourages adoption of a healthy lifestyle. A census of the SDA membership was undertaken to identify all non-Hispanic whites residing in California in 1974, to which 59081 members responded. In 1976-1977, a lifestyle questionnaire (I) was sent to the census respondents who were 25 years and older. The 34198 respondents to the questionnaire formed the cohort, which was followed for 12 years. The details of the census and the AHS- 1 have been described elsewhere ${ }^{24}$. This study cohort includes a fairly wide range of meat intake as well as a substantial segment (approximately 50\%) that adheres to a vegetarian diet, which offers a unique opportunity to study bone health relative to a wide range of dietary practices.

\section{Adventist Health Study 2 (2002-date)}

The purpose of the second Adventist Health Study (AHS2 ) is to extend the investigation of the effects of lifestyle choices on health in black as well as a larger number of white members of the SDA church throughout the USA and Canada. Recruitment efforts among the church membership have included announcements and media presentations at weekly church services, advertisements in SDA periodicals, brochures, and interviews on SDA television networks. Interested members who turned in an enrolment card and were 35 years or older received the lifestyle questionnaire (II). The 5-year (2002-2006) recruitment campaign was to be carried out across the country in phases, with the earliest phase including the churches in the state of California. By the summer of 2004, it was determined that the campaign in California was largely complete.

\section{Record linkage}

In an effort to identify respondents who may have participated in both the first and second lifestyle surveys, the AHS-2 lifestyle questionnaire asked if the respondent recalled participating in the 1976 survey. A request for a maiden name and the last name that was used in 1983 (the last annual follow-up of AHS-1) was also made of female respondents. A matching process involving several steps was developed to link the appropriate records from the AHS- 1 and AHS- 2 surveys, since the AHS- 1 survey did not have a common numerical identifier such as a social security number. Ultimately 14 variables were used to determine a match of records: first, middle and last name; month, day and year of birth; state or country of birth; recalled age at baptism into the church; recalled participation in AHS-1; marital status; maiden name; last name used in 1982; birth year of first child; and last name of contact person. A number of computerised algorithms using the first 10 of these variables were developed and employed to identify potential matches of women participating in the two studies. All lists of potential matches identified in this manner were individually reviewed by one of the authors (D.L.T.) to identify highly probable matches. Pairs differing on more than one critical variable were subsequently reviewed by a panel of three members. The final determination by consensus was reached with the aid of information on the last five variables. The final number of matching records on females who responded to both the AHS-1 and AHS-2 questionnaires was 3209.

In this cohort of women, 1406 were menopausal at baseline (1976). This included women who experienced surgical menopause as early as age 25 years, as well as those experiencing early but natural menopause. Another 459 women were not yet menopausal but were 45 years of age or older. They were considered perimenopausal in that age 45 was two standard deviations below the current mean age for menopause in AHS-2. This is consistent with the definition for the perimenopausal period used in other studies ${ }^{1,5}$. Together, the total of 1865 women comprised the study population.

\section{Baseline data collection}

The AHS-1 lifestyle questionnaire provided baseline demographic and lifestyle data on education, body mass index (BMI), practitioner-diagnosed medical conditions 
(coronary heart disease, stroke, high blood pressure, diabetes, diverticulitis, cancer, rheumatoid arthritis, other arthritis), alcohol use, smoking, nulliparity, menopausal status, age at menopause, hormone use and physical activity. Menopausal status for women aged less than 60 years who indicated they were still menstruating regularly or irregularly was accepted as perimenopausal. Women older than 59 years who still reported menstruating were considered postmenopausal. Women who failed to respond to questions regarding menopausal status at baseline were considered menopausal at 60 years, unless they indicated an earlier age of menopause on the AHS-2 lifestyle questionnaire. Baseline hormone use, alcohol use and smoking were assessed as never, past or current.

For physical activity, the questionnaire included 10 items on work-, recreational- and leisure-related physical activity. Eight of these items asked respondents if they participated in any of the listed vigorous leisure activities such as cycling and gardening for at least 15 minutes on three or more occasions per week, or any other activity for the same duration and frequency. The last two items assessed participation in regular vigorous activity for less than 15 minutes and the frequency of work-related vigorous activity. From these items a three-level index for occupational and leisure exercise was developed. Low, moderate and high level of physical activity corresponded to any leisure exercise of $<15 \mathrm{~min} 3 \times /$ week; moderateintensity leisure such as tennis and gardening $>15 \mathrm{~min}$ $3 \times /$ week; and $\geq 15 \mathrm{~min}$ of high-intensity exercise (e.g. cycling, swimming) $\geq 3 \times /$ week, respectively. Daily work involving vigorous activity 'very often' also qualified as a high level of physical activity.

The dietary portion of the questionnaire consisted of 65 semi-quantitative food items with the following eightlevel food frequency response format for most items: never, $<1 \times /$ month, $1-2 \times /$ month, $1-2 \times /$ week, $3-4 \times /$ week, 5-6 $\times /$ week, daily, $>1 \times /$ daily. For the four milk items, the response format was modified as follows: never, $<1 \times /$ week, several times/week, $1 \times /$ day, $2-3 \times /$ day, $4-5 \times /$ day, $>5 \times /$ day. The validity of the food frequency portion of the questionnaire was tested in a group of 147 members of the cohort who provided dietary information on five 24-hour dietary recalls on random days over a 3-month period, but which included both weekdays and weekends. The validity study has been described in detail elsewhere ${ }^{25}$. The lifestyle questionnaire generally did not ask for the portion size of a particular food item ingested.

\section{Follow-up data collection}

The AHS-2 lifestyle questionnaire provided data on fractures due to minor trauma at the wrist, humerus, hip, thigh, leg and ankle experienced since 35 years of age. Respondents who indicated that they had experienced any of these fractures due to minor trauma since age 35 were asked to specify the approximate time frame for the first occurrence of each of the six categories of fracture. The seven closed-ended responses for how long ago the fracture occurred were: $<1$ year, 1-4 years, 5-9 years, 10-14 years, 15-19 years, 20-25 years, $>25$ years. Fractures that were reported to have occurred more than 25 years ago were considered prevalent fractures at baseline (i.e. 1976).

\section{Statistical methods}

The dietary analysis included individual food items from the questionnaire. In addition, five indices representing different food groups were used. Four of the five indices were constructed by summing the frequency of intake for foods in the group using midpoint frequencies for particular categories. Then those sums were again categorised. The fifth index, meat intake, was constructed using the summed frequency of five items on beef, poultry, fish and pork consumption and the response to a single question on frequency of overall meat consumption. The meat intake index reflected the higher meat intake if the summed frequency of various meat intake differed from the single question on meat consumption. Three levels of intake were specified for each of the selected foods (cheese, cottage cheese, eggs, milk, salad, green vegetables, nuts, beans, vegetarian meat substitute products typically made from wheat gluten or soybean textured protein) and food groups (meat, fruit, fruits and vegetables, vegetable-protein foods, animal-protein foods). In most cases, the low, medium and high categories corresponded to approximately the 20th, 50th and 80th percentiles of intake, respectively.

The independent $t$-test for means and Pearson's $\chi^{2}$ test for categorical data were used to test for differences in demographic and lifestyle variables between cases and non-cases. The effects of foods high in protein and other covariates on WF risk were assessed using Cox proportional-hazard regression with attained age as the time variable $^{26}$. Attained age for WF cases was estimated at the midpoint of the time interval specified for the event on the AHS-2 questionnaire. Covariates were entered into univariate and multivariable models as dummy variables except for years since menopause, which was entered as a time-dependent covariate. In univariate models these included age, BMI, height, weight, education, any fracture since age 35, parity, smoking status, alcohol use, presence of diabetes mellitus, presence of rheumatoid arthritis and physical activity. All variables were measured at baseline except for fracture since age 35 and years since menopause. For multivariable modelling of main effects, a base model was constructed with the three food variables high in protein (nuts, beans, meat substitutes), physical activity, hormone use and BMI (covariates often shown in the literature to be strongly associated with risk of fracture), and education. The last variable was forced into the 
model to control for socio-economic status. Correlates that altered the main effect of vegetarian status (vegetarian, semi-vegetarian, non-vegetarian) by $10 \%$ or that showed an independent effect on WF $(P<0.05)$ were retained in the final multivariable model for all subjects. Multivariable high-protein foods-only models with interactions between the food variables were also explored. Lastly, significant food interaction terms were added to the final multivariable model. SAS (Statistical Analysis System, version 8.0) was used for all analyses. Visual inspection of the log-log survival plot, and also a nonsignificant interaction term between the three-level vegetarian status and log time temporarily added to the final model, confirmed that the proportional hazards assumption for the Cox regression model was met.

\section{Results}

A total of 216 WFs occurred after the age of 35 in this peri- and postmenopausal cohort. Of these, 45 were considered prevalent fractures as they were reported as occurring more than 25 years earlier (i.e. before completion of the AHS-1 lifestyle questionnaire). Five individuals sustained two incident WFs. The 25-year period-incidence rate for WF was 3.7/1000 person-years. The incidence rate by age group detailed in Table 1 shows a continuously increasing risk with age. Table 2 compares cases with non-cases on selected variables. Cases were more likely to be older, have a history of fractures, report low or no vigorous physical activity, have experienced menopause more than 15 years earlier, have never used hormones, and to be nulliparous. There were no significant differences on baseline height, weight, BMI, level of education, prevalence of any co-morbidity, alcohol use or smoking. Comparisons were also made between cases and non-cases on selected foods high in protein (cheese, cottage cheese, eggs, milk, meat, beans, nuts, vegetarian meat analogues, soy milk) and on fruit, green vegetables and salad (data not shown). Cases and non-cases differed in intake of three food items: cottage cheese, cheese and meat, with cases consuming cheese and meat less frequently. The relationship with cottage cheese was less clear.

Multivariable effects of single high-protein foods and food groups on WF risk at time of fracture and attained age, as well as effects of established confounders, are examined in Table 3. In this model without interaction terms, cheese and meat intake were strongly protective in a dose-response manner against risk of WF ( $P$ for trend $=0.05$ for cheese, 0.02 for meat). Cheese intake $>3 \times /$ week reduced the risk of fracture by $58 \%(95 \%$ confidence interval (CI) 0.18-0.98), while meat consumption $>4 \times /$ week reduced the risk by $56 \%$ (95\% CI 0.23-0.84). The vegetable protein food group did not show an independent effect on fracture risk. Four nondietary factors that showed important effects on fracture risk were hormone use, physical activity, any fracture since age 35 and years since menopause. Hormone use and physical activity were significantly associated with decreased risk, whereas years since menopause significantly increased risk. The elevated risk related to any fracture since age 35 did not reach significance. Since multivariable model effects differed little from univariate effects, data from univariate analyses are not shown.

Exploration of foods-only models with interaction terms between foods revealed a significant interaction between the three-level meat intake and vegetable protein variables $(P=0.004)$. The group at highest risk for fracture were those who never consume meat (vegetarians) and in the lowest category of vegetable protein intake (Table 4). Among vegetarians, increasing vegetable protein clearly reduced risk of fracture, with a reduction in risk of $68 \%$ (hazard ratio $(\mathrm{HR})=0.32,95 \%$ CI 0.13-0.79) in the highest intake group. Similarly, among those with the lowest vegetable protein consumption, increasing meat intake decreased the risk of WF, with the highest consumption decreasing risk by $80 \%$ ( $\mathrm{HR}=0.20$, 95\% CI 0.06-0.66). The basis of the interaction seems to be that, in contrast, in medium or high meat consumers, higher vegetable protein appeared to increase risk. As might be expected, there were very few subjects in the highest category of meat and vegetable protein intake, which produced a very unstable estimate. When the food model with interaction terms was adjusted for the four non-dietary variables in the base model of main effects and for fruit and vegetable intake, diabetes, rheumatoid arthritis, ever pregnant, smoking and alcohol intake, the interaction term remained significant $(P=0.005)$.

Examination of the diets of vegetarians and nonvegetarians for the six foods high in protein revealed very different consumption patterns (Table 5). Vegetarians

Table 1 Incidence of first wrist fracture per 1000 person-years by age group among women who were either 45 years of age and older or postmenopausal at baseline

\begin{tabular}{lcccc}
\hline Age group (years) & No. of subjects & Person-years & No. of fractures & Incidence per 1000 person-years \\
\hline$<50$ & 733 & 18398 & 57 & 3.1 \\
$50-59$ & 869 & 21632 & 85 & 3.9 \\
$>59$ & 263 & 6505 & 29 & 4.4 \\
Overall & 1865 & 46535 & 171 & 3.7 \\
\hline
\end{tabular}


Table 2 Selected demographic and lifestyle characteristics of wrist fracture cases and non-cases at baseline in 1976 among women in the Adventist Health Study who were menopausal or 45 years of age and older

\begin{tabular}{|c|c|c|c|}
\hline & Cases $(n=171)$ & Non-cases $(n=1694)$ & $P$ \\
\hline Age (years), mean (SD) & $53.9(7.2)$ & $52.0(7.3)$ & $<0.0001^{\star}$ \\
\hline Height (in), mean (SD) & $64.3(2.5)$ & $64.5(2.6)$ & $0.21^{*}$ \\
\hline Weight (Ib), mean (SD) & $140.1(25.2)$ & $142.1(24.0)$ & $0.82^{*}$ \\
\hline BMI $\left(\mathrm{kg} \mathrm{m}^{-2}\right)$, mean (SD) & $23.9(4.1)$ & $24.0(3.9)$ & $0.13^{\star}$ \\
\hline \multicolumn{4}{|l|}{ Education } \\
\hline High school graduate or less & $44(25.7)$ & $409(24.1)$ & \multirow[t]{3}{*}{$0.88+$} \\
\hline Some college & $84(49.1)$ & $831(49.1)$ & \\
\hline College graduate or higher & $43(23.2)$ & $448(26.4)$ & \\
\hline \multicolumn{4}{|l|}{ Hormone use, $n(\%)$} \\
\hline Never & $82(48.0)$ & $676(39.9)$ & \multirow[t]{3}{*}{$0.03+$} \\
\hline Past & $34(19.9)$ & $353(20.8)$ & \\
\hline Current & $46(26.9)$ & $635(37.5)$ & \\
\hline \multicolumn{4}{|l|}{ Years since menopause, $n(\%)$} \\
\hline Perimenopausal & $41(24.0)$ & $418(24.7)$ & \multirow[t]{3}{*}{$0.006+$} \\
\hline $1-15$ years & $88(51.5)$ & $1010(59.6)$ & \\
\hline$>15$ years & $42(24.6)$ & $256(15.1)$ & \\
\hline \multicolumn{4}{|l|}{ Physical activity index, $n(\%)$} \\
\hline Low or none & $91(53.2)$ & $744(43.9)$ & \multirow[t]{3}{*}{$0.06+$} \\
\hline Moderate & $27(15.8)$ & $293(17.3)$ & \\
\hline High & $52(30.4)$ & $641(37.8)$ & \\
\hline History of fractures, $n(\%)$ & $18(10.5)$ & $98(5.8)$ & $0.01 t$ \\
\hline Nulliparity, $n(\%)$ & $25(14.6)$ & $190(11.2)$ & $0.19+$ \\
\hline \multicolumn{4}{|l|}{ Co-morbidities, $n$ (\%) } \\
\hline Asthma & $10(5.8)$ & $100(5.9)$ & $0.97 \dagger$ \\
\hline Coronary heart disease & $1(0.6)$ & $19(1.1)$ & $0.52 \dagger$ \\
\hline Cancer & $11(6.4)$ & $87(5.1)$ & $0.41 \dagger$ \\
\hline Hypertension & $30(18.2)$ & $268(16.4)$ & $0.55 t$ \\
\hline Rheumatoid arthritis & $5(2.9)$ & $69(4.1)$ & $0.46+$ \\
\hline Stroke & $0(0.0)$ & $1(0.06)$ & $0.75 t$ \\
\hline Use alcohol, $n(\%)$ & $6(3.5)$ & $91(5.4)$ & $0.30+$ \\
\hline Smoker, $n(\%)$ & $20(11.7)$ & $199(11.8)$ & $0.98+$ \\
\hline
\end{tabular}

SD - standard deviation; BMI - body mass index.

*Independent $t$-test.

$+\chi^{2}$ test.

consumed beans, nuts and meat analogues more frequently than non-vegetarians whereas the frequency of cheese intake was higher for non-vegetarians. In vegetarians, the risk of WF decreased with the frequency of consumption for each of the foods high in protein. For non-vegetarians the risk tended to decrease with meat consumption and increase with intake of each of the plant-based protein foods.

\section{Discussion}

The incidence of low-trauma WF of $3.7 / 1000$ in this cohort appears to be low, although an appropriate basis for comparison is difficult to find. Regional statistics do not differentiate between low and high trauma cases. Cohort studies that have identified low-energy WF have reported incidences that range from 1.2 to $12.5 / 1000$ person-years ${ }^{3,5,6,27}$. In part, this range of incidence values reflects the age of the cohort studied. Two studies that included women as young as 28 and 34 years reported WF incidences of 3.40 and $1.22 / 1000$ person-years, respectively ${ }^{3,27}$. A study of perimenopausal women aged 45-57 years at baseline reported a WF incidence of
6.5/1000 person-years ${ }^{5}$. The years of follow-up in these three studies ${ }^{3,5,27}$ ranged from 4.7 to 8 years, a relatively short follow-up compared with the 25.2 years in the present study. The National Osteoporosis Risk Assessment (NORA) study, which has the largest cohort of white women in the USA to date for the study of osteoporosis, may provide the best age, ethnic and national comparison $^{28}$. When both study populations are directly agestandardised to the 2000 US population structure, the incidence of WF in women aged 50-80 years is 6.7/1000 in NORA and 4.5/1000 in the present study.

The relatively low incidence may be related to the high and long-term use of hormones in this study population, a practice consistently shown to have a protective bene$\mathrm{fit}^{1,5-7,9,29}$. Less than $42 \%$ had never used hormones. The estimate for mean duration for hormone use among past or current users at baseline was 5.1 years. In addition, use has increased over the 25 -year period, with recalled use averaging more than 15 years for ever users.

Alternatively, the low incidence may represent underreporting of WF, but this is not likely. WF has been shown to be reliably recalled and is deemed useful for epidemiological studies ${ }^{27,30,31}$. Honkanen et al $^{30}$ reported sensitivity and specificity of $95 \%$ and $99.5 \%$, respectively. 
Table 3 Multivariate adjusted model for the effects of foods and known covariates without interaction terms on the risk of wrist fracture among women in the Adventist Health Study who were postmenopausal or 45 years and older at baseline

\begin{tabular}{|c|c|c|c|c|}
\hline Covariate & No. of women & No. of fractures & $\mathrm{HR}(95 \% \mathrm{Cl})$ & $P$ for trend ${ }^{*}$ \\
\hline \multicolumn{5}{|l|}{ Physical activity index } \\
\hline Low or none & 835 & 91 & 1.00 & \multirow[t]{3}{*}{0.003} \\
\hline Moderate & 320 & 27 & $0.73(0.47-1.15)$ & \\
\hline High & 693 & 52 & $0.59(0.41-0.84)$ & \\
\hline \multicolumn{5}{|l|}{ Hormone use } \\
\hline Never & 758 & 82 & 1.00 & \multirow[t]{3}{*}{0.0002} \\
\hline Past & 387 & 34 & $0.61(0.40-0.93)$ & \\
\hline Current & 681 & 46 & $0.49(0.33-0.71)$ & \\
\hline \multicolumn{5}{|l|}{ Any fracture* since age 35} \\
\hline No & 1511 & 98 & 1.00 & \\
\hline Yes & 354 & 18 & $1.43(0.84-2.41)$ & \\
\hline Years since menopauset & & & $1.02(1.00-1.05)$ & \\
\hline \multicolumn{5}{|l|}{ Cheese } \\
\hline$<1 \times /$ week & 206 & 34 & 1.00 & \multirow[t]{3}{*}{0.05} \\
\hline $1-3 \times /$ week & 1328 & 130 & $0.71(0.46-1.09)$ & \\
\hline$>3 \times /$ week & 160 & 7 & $0.42(0.18-0.98)$ & \\
\hline \multicolumn{5}{|l|}{ Meat } \\
\hline Never & 718 & 81 & 1.00 & \multirow[t]{3}{*}{0.02} \\
\hline$<1-4 \times /$ week & 840 & 74 & $0.87(0.62-1.24)$ & \\
\hline$>4 \times /$ week & 299 & 14 & $0.44(0.23-0.84)$ & \\
\hline \multicolumn{5}{|l|}{ Vegetable protein $\S$} \\
\hline$<3 \times /$ week & 304 & 22 & 1.00 & \multirow[t]{3}{*}{0.31} \\
\hline $3-7 \times /$ week & 1218 & 120 & $1.04(0.63-1.71)$ & \\
\hline$>1 \times /$ day & 343 & 29 & $0.79(0.43-1.46)$ & \\
\hline \multicolumn{5}{|l|}{$\mathrm{BMI}\left(\mathrm{kg} \mathrm{m}^{-2}\right)$} \\
\hline$<21.6$ & 627 & 54 & 1.00 & \multirow[t]{3}{*}{0.92} \\
\hline $21.6-25.0$ & 714 & 74 & $1.19(0.82-1.73)$ & \\
\hline$>25.0$ & 524 & 43 & $1.06(0.67-1.66)$ & \\
\hline \multicolumn{5}{|l|}{ Education } \\
\hline High school graduate or less & 453 & 44 & 1.00 & \multirow[t]{3}{*}{0.77} \\
\hline Some college & 915 & 84 & $1.07(0.68-1.68)$ & \\
\hline College graduate or higher & 491 & 43 & $1.10(0.75-1.61)$ & \\
\hline
\end{tabular}

$\mathrm{HR}$ - hazard ratio; $\mathrm{Cl}$ - confidence interval; $\mathrm{BMI}$ - body mass index.

* Time-dependent covariate.

tAny fracture of arm, elbow, forearm, hip, thigh, leg or ankle.

$\ddagger$ Beef, pork, poultry, fish.

$\S$ Beans, nuts, vegetarian meat analogues.

Table 4 Interaction of effects of vegetable protein and meat intake on risk of a wrist fracture among women in the Adventist Health Study who were postmenopausal or 45 years and older at baseline

\begin{tabular}{|c|c|c|c|c|c|c|}
\hline \multirow[b]{3}{*}{ Vegetable protein } & \multirow[b]{3}{*}{ No. of women } & \multirow[b]{3}{*}{ No. of fractures } & \multicolumn{3}{|c|}{ Meat intake } & \multirow[b]{3}{*}{$P$ for interaction } \\
\hline & & & None & $<1-4 \times /$ week & $>4 \times /$ week & \\
\hline & & & $\mathrm{HR}(95 \% \mathrm{Cl})$ & $\mathrm{HR}(95 \% \mathrm{Cl})$ & $\mathrm{HR}(95 \% \mathrm{Cl})$ & \\
\hline$<3 \times /$ week & 304 & 22 & 1.00 & $0.39(0.15-1.07)$ & $0.20(0.06-0.66)$ & 0.005 \\
\hline $3 \times /$ week $-1 \times /$ day & 1218 & 120 & $0.62(0.30-1.32)$ & $0.49(0.23-1.06)$ & $0.32(0.12-0.86)$ & \\
\hline$>1 \times /$ day & 343 & 29 & $0.32(0.13-0.79)$ & $0.66(0.27-1.60)$ & - & \\
\hline
\end{tabular}

$\mathrm{HR}$ - hazard ratio; $\mathrm{Cl}$ - confidence interval.

In a study of 251 fracture cases, only 3\% of hip and wrist fractures were not reported.

The study finding that higher frequencies of foods rich in protein in the diet were associated with reduced WF risk for vegetarian and non-vegetarian dietary patterns supports the growing evidence of the importance of adequate protein for bone health. Strong correlations between intake of protein and spine, total body and midradius $\mathrm{BMD}$ have been noted in premenopausal vege- tarians and omnivores in the USA and to a lesser extent in postmenopausal women ${ }^{32-34}$. Similarly, at least four cohort studies $^{35-38}$ and one clinical trial ${ }^{39}$ have demonstrated a dose-response relationship between total protein intake and either increased BMD or decreased bone loss. Risk of hip fracture was also negatively associated with total dietary protein in the Iowa Women's Study ${ }^{40}$. Low protein intake has frequently been noted among patients admitted with a hip fracture and is associated 
Table 5 Hazard ratios for selected high-protein foods and forearm fracture, stratified by vegetarian status, among women in the Adventist Health Study who were postmenopausal or 45 and older at baseline

\begin{tabular}{|c|c|c|c|c|c|c|}
\hline \multirow[b]{2}{*}{ Food/Food index } & \multicolumn{2}{|c|}{ Vegetarians $(n=718)$} & \multirow[b]{2}{*}{$P$ for trend ${ }^{*}$} & \multicolumn{2}{|c|}{ Non-vegetarians $(n=1142)$} & \multirow[b]{2}{*}{$P$ for trend ${ }^{*}$} \\
\hline & $\%$ of women & $\mathrm{HR}(95 \% \mathrm{Cl})$ & & $\%$ of women & $\mathrm{HR}(95 \% \mathrm{Cl})$ & \\
\hline \multicolumn{7}{|l|}{ Food } \\
\hline \multicolumn{7}{|l|}{ Cheese } \\
\hline$<1 \times /$ week & 22.4 & 1.00 & 0.03 & 6.5 & 1.00 & 0.10 \\
\hline $1-3 \times /$ week & 72.4 & $0.63(0.38-1.05)$ & & 82.1 & $0.79(0.37-1.72)$ & \\
\hline$>3 \times /$ week & 5.2 & $0.31(0.07-1.38)$ & & 11.4 & $0.38(0.12-1.23)$ & \\
\hline \multicolumn{7}{|l|}{ Beans } \\
\hline$<1 \times /$ month & 5.7 & 1.00 & 0.01 & 17.1 & 1.00 & 0.58 \\
\hline $1 \times /$ month to $1-2 \times /$ week & 65.6 & $0.57(0.27-1.19)$ & & 67.3 & $1.01(0.56-1.83)$ & \\
\hline$>2 \times /$ week & 28.7 & $0.35(0.15-0.82)$ & & 15.6 & $1.24(0.59-2.60)$ & \\
\hline \multicolumn{7}{|l|}{ Nuts } \\
\hline$<1 \times /$ month & 7.5 & 1.00 & 0.19 & 16.9 & 1.00 & 0.22 \\
\hline $1 \times /$ month to $6 \times /$ week & 67.8 & $0.60(0.30-1.22)$ & & 70.2 & $1.25(0.66-2.37)$ & \\
\hline$>1 \times /$ day & 24.7 & $0.47(0.21-1.05)$ & & 12.9 & $1.64(0.74-3.63)$ & \\
\hline \multicolumn{7}{|l|}{ Meat analogues } \\
\hline$<1 \times /$ month & 17.2 & 1.00 & 0.05 & 42.2 & 1.00 & 0.01 \\
\hline $1-4 \times /$ week & 57.8 & $0.79(0.47-1.35)$ & & 45.8 & $1.63(1.02-2.61)$ & \\
\hline$>4 \times /$ week & 24.8 & $0.54(0.27-1.08)$ & & 12.0 & $2.22(1.18-4.17)$ & \\
\hline \multicolumn{7}{|l|}{ Food index } \\
\hline \multicolumn{7}{|l|}{ Vegetable proteint } \\
\hline$<3 \times /$ week & 6.0 & 1.00 & 0.04 & 22.4 & 1.00 & 0.009 \\
\hline $3-7 \times /$ week & 65.7 & $0.66(0.32-1.39)$ & & 65.3 & $2.19(1.16-4.15)$ & \\
\hline$>1 \times /$ day & 28.3 & $0.32(0.13-0.76)$ & & 12.3 & $2.51(1.29-4.87)$ & \\
\hline \multicolumn{7}{|l|}{ Meat } \\
\hline$<1 \times /$ month & & & & 40.8 & 1.00 & 0.15 \\
\hline $1-4 \times /$ week & & & & 32.9 & $1.17(0.72-1.89)$ & \\
\hline$>4 \times /$ week & & & & 26.3 & $0.57(0.30-1.07)$ & \\
\hline \multicolumn{7}{|l|}{ Fruits \& vegetables } \\
\hline$<2 \times /$ day & 11.4 & 1.00 & 0.76 & 18.3 & 1.00 & 0.74 \\
\hline $2-5 \times /$ day & 68.1 & $0.51(0.27-0.98)$ & & 68.8 & $1.68(0.87-3.25)$ & \\
\hline$>5 \times /$ day & 20.5 & $0.76(0.36-1.60)$ & & 12.9 & $1.07(0.43-2.66)$ & \\
\hline
\end{tabular}

$\mathrm{HR}$ - hazard ratio; $\mathrm{Cl}$ - confidence interval.

${ }^{*}$ Log likelihood $\chi^{2}$ test.

tBeans, nuts, soy milk, vegetarian meat analogues.

with bone $\operatorname{loss}^{41}$. Protein supplements were found to attenuate proximal femoral bone loss in a randomised, double-blind, placebo-controlled study of patients with a recent hip fracture ${ }^{42}$.

Despite the fact that vegetarians with the lowest intake of foods high in vegetable protein were at the highest risk for WF, it is important to note that being a vegetarian in this cohort was not a risk factor when risk was adjusted for all covariates. Among vegetarians it is clear that each of the three vegetable sources high in protein separately and together are effectively associated with reduced fracture risk. The similarity in risk reduction by these protein foods compared with the risk reduction associated with meat intake suggests that adequate protein intake is quite attainable in a vegetarian diet.

The observation that increasing vegetable protein intake among meat-eaters appeared to be hazardous in the presence of meat is puzzling, but not without precedent. Increased risk of hip fracture was also noted in the Iowa Women's Study ${ }^{40}$ with increasing vegetable protein intake. We can only speculate on the reason for this finding. Many of the processed gluten-based protein foods consumed are high in sodium which competes with calcium for renal resorption. Alternatively, if vegetable and fruit intake is inadequate among meat consumers, adding nuts and grains - many of which have high potential renal acid loads - to an otherwise already adequate protein intake from meat may enhance risk through chronic low-level metabolic acidosis ${ }^{41}$. However, this explanation is not compelling as there were no interactions between intake of either meat or vegetable protein foods and intake of fruits and vegetables.

To assess the role of diet in bone health, the need for research at the level of whole foods and dietary patterns is becoming increasingly apparent ${ }^{43-45}$. The present study, in a population with a wide diversity in dietary patterns and a substantial proportion of vegetarians, offers a unique opportunity to compare the long-term effects of foods high in protein from animal and vegetable sources. Several implications relative to diet and fracture risk may be drawn. First, in light of the relatively low incidence of WF in this study, a vegetarian diet or diet relatively low in meat consumption does not appear to increase the risk of WF relative to the general population and it may in fact lower the risk of fracture relative to the general population, so long as the diet is high in protein. 
Second, those who consume a vegan or vegetarian diet may be at increased risk of fracture unless care is taken to ensure that an adequate quantity and variety of foods high in protein, such as grains, nuts and legumes, are in the diet in addition to plenty of fruits and vegetables.

The inference of causal relationships between diet and risk of distal forearm fracture is limited by the observational nature of this study, the measurement error inherent in a questionnaire of dietary intake assessed only once in 25 years, and the fact that intake of cereals and grains was largely not assessed. However, differential misclassification of dietary intake of foods in relation to outcome is unlikely as exposure was assessed prospectively. The resulting assumed non-differential misclassification of dietary exposures in the study is likely to attenuate the true relationships between dietary intake patterns and fracture risk. It is also possible that the subjects who survived and chose to participate in AHS-2 were healthier and genetically better endowed than subjects who did not, but there is no evidence that this is so. And finally, the findings in this study population of Caucasian women may not be broadly generalisable to women of other ethnicities.

In conclusion, in this 25-year span of dietary effects of whole foods on risk of fracture, foods high in protein including beans, nuts, vegetarian meat analogues and cheese - reduced the risk of distal forearm fractures in peri- and postmenopausal vegetarian women. When all subjects were analysed together, vegetarian women were not at higher risk for WF than non-vegetarian women. More research is needed to identify salutary and detrimental dietary patterns relative to fracture risk and to clarify the role of high-protein foods from animal and plant sources in bone health.

\section{Acknowledgements}

Sources of funding: This work was supported by grants no. 2R01-CA14703-15 and 5R01 CA094594 from the National Cancer Institute.

Conflict of interest declaration: None of the authors had any conflict of interest.

Authorship responsibilities: D.L.T. and S.F.K. conceptualised the study. D.L.T. identified the study subjects, conducted the analyses and prepared the manuscript. W.L.B. asssisted in identifying subjects, provided statistical and data management expertise and refining of manuscript drafts. S.R. provided nutritional consultation and review of the final draft. S.F.K. provided overall guidance in interpretation and manuscript writing. G.E.F. contributed statistical advice and provided consultation on the final draft.

Acknowledgements: David Shavlik, MSPH, Assistant Professor in the Epidemiology Department, School of
Allied Health Professions, Loma Linda University, provided invaluable assistance in developing algorithms for the process of identifying matching records of women in the two Adventist Health Studies. He also served as member of the panel to determine the final matching dataset. In addition, Mark Ghamsary, PhD, Director of the Biostatistics Program, was instrumental at a key juncture in the data analysis.

\section{References}

1 Kelsey JL, Prill MM, Keegan TH, Tanner HE, Bernstein AL, Quesenberry CP Jr, et al. Reducing the risk for distal forearm fracture: preserve bone mass, slow down, and don't fall! Osteoporosis International 2005; 16: 681-90.

2 Haentjens P, Autier P, Collins J, Velkeniers B, Vanderschueren $\mathrm{D}$, Boonen $\mathrm{S}$. Colles fracture, spine fracture, and subsequent risk of hip fracture in men and women. $A$ meta-analysis. Journal of Bone and Joint Surgery. American volume 2003; 85-A: 1936-43.

3 Hernandez-Avila M, Colditz GA, Stampfer MJ, Rosner B, Speizer FE, Willett WC. Caffeine, moderate alcohol intake, and risk of fractures of the hip and forearm in middle-aged women. American Journal of Clinical Nutrition 1991; 54: 157-63.

4 Nguyen TV, Center JR, Sambrook PN, Eisman JA. Risk factors for proximal humerus, forearm, and wrist fractures in elderly men and women: the Dubbo Osteoporosis Epidemiology Study. American Journal of Epidemiology 2001; 153: 587-95.

5 Honkanen RJ, Honkanen K, Kroger H, Alhava E, Tuppurainen M, Saarikoski S. Risk factors for perimenopausal distal forearm fracture. Osteoporosis International 2000; 11: $265-70$

6 Vogt MT, Cauley JA, Tomaino MM, Stone K, Williams JR, Herndon JH. Distal radius fractures in older women: a 10year follow-up study of descriptive characteristics and risk factors. The study of osteoporotic fractures. Journal of the American Geriatrics Society 2002; 50: 97-103.

7 Hundrup YA, Hoidrup S, Ekholm O, Davidsen M, Obel EB. Risk of low-energy hip, wrist, and upper arm fractures among current and previous users of hormone replacement therapy: The Danish Nurse Cohort Study. European Journal of Epidemiology 2004; 19: 1089-95.

8 Feskanich D, Willett WC, Stampfer MJ, Colditz GA. Protein consumption and bone fractures in women. American Journal of Epidemiology 1996; 143: 472-9.

9 Ivers RQ, Cumming RG, Mitchell P, Peduto AJ. Risk factors for fractures of the wrist, shoulder and ankle: the Blue Mountains Eye Study. Osteoporosis International 2002; 13: 513-18.

10 Malm OJ. On phosphates and phosphoric acid as dietary factors in the calcium balance of man. Scandinavian Journal of Clinical and Laboratory Investigation 1953; 5: 75-84.

11 New SA. Intake of fruit and vegetables: implications for bone health. Proceedings of the Nutrition Society 2003; 62: 889-99.

12 Nieves JW. Osteoporosis: the role of micronutrients. American Journal of Clinical Nutrition 2005; 81: 1232S-9S.

13 Tucker KL. Dietary intake and bone status with aging. Current Pharmaceutical Design 2003; 9: 2687-704.

14 Wengreen HJ, Munger RG, West NA, Cutler DR, Corcoran $\mathrm{CD}$, Zhang $\mathrm{J}$, et al. Dietary protein intake and risk of osteoporotic hip fracture in elderly residents of 
Utah. Journal of Bone and Mineral Research 2004; 19 $537-45$.

15 Kato I, Toniolo P, Zeleniuch-Jacquotte A, Shore RE, Koenig $\mathrm{KL}$, Akhmedkhanov A, et al. Diet, smoking and anthropometric indices and postmenopausal bone fractures: a prospective study. International Journal of Epidemiology 2000; 29: 85-92.

16 Trichopoulou A, Georgiou E, Bassiakos Y, Lipworth L, Lagiou $\mathrm{P}$, Proukakis $\mathrm{C}$, et al. Energy intake and monounsaturated fat in relation to bone mineral density among women and men in Greece. Preventive Medicine 1997; 26: 395-400.

17 Macdonald HM, New SA, Golden MH, Campbell MK, Reid DM. Nutritional associations with bone loss during the menopausal transition: evidence of a beneficial effect of calcium, alcohol, and fruit and vegetable nutrients and of a detrimental effect of fatty acids. American Journal of Clinical Nutrition 2004; 79: 155-65.

18 Zhang X, Shu XO, Li H, Yang G, Li Q, Gao YT, et al. Prospective cohort study of soy food consumption and risk of bone fracture among postmenopausal women. Archives of Internal Medicine 2005; 165: 1890-5.

19 Feskanich D, Singh V, Willett WC, Colditz GA. Vitamin A intake and hip fractures among postmenopausal women. JAMA: Journal of the American Medical Association 2002; 287: $47-54$

20 Dhonukshe-Rutten RA, Pluijm SM, de Groot LC, Lips P, Smit $\mathrm{JH}$, van Staveren WA. Homocysteine and vitamin $\mathrm{B}_{12}$ status relate to bone turnover markers, broadband ultrasound attenuation, and fractures in healthy elderly people. Journal of Bone and Mineral Research 2005; 20: 921-9.

21 Kerstetter JE, O'Brien KO, Insogna KL. Dietary protein, calcium metabolism, and skeletal homeostasis revisited. American Journal of Clinical Nutrition 2003; 78: 584S-92S.

22 Cade JE, Burley VJ, Greenwood DC. The UK Women's Cohort Study: comparison of vegetarians, fish-eaters and meat-eaters. Public Health Nutrition 2004; 7: 871-8.

23 Tesar R, Notelovitz M, Shim E, Kauwell G, Brown J. Axial and peripheral bone density and nutrient intakes of postmenopausal vegetarian and omnivorous women. American Journal of Clinical Nutrition 1992; 56 : 699-704.

24 Beeson WL, Mills PK, Phillips RL, Andress M, Fraser GE. Chronic disease among Seventh-day Adventists, a low-risk group. Rationale, methodology, and description of the population. Cancer 1989; 64: 570-81.

25 Fraser GE, Sabate J, Beeson WL, Strahan TM. A possible protective effect of nut consumption on risk of coronary heart disease. The Adventist Health Study. Archives of Internal Medicine 1992; 152: 1416-24.

26 Kelsey JL, Thompson WD, Evans AS. Methods in Observational Epidemiology. New York: Oxford University Press, 1986.

27 Joakimsen RM, Fonnebo V, Magnus JH, Stormer J, Tollan A, Sogaard AJ. The Tromso Study: physical activity and the incidence of fractures in a middle-aged population. Journal of Bone and Mineral Research 1998; 13: 1149-57.

28 Miller PD, Siris ES, Barrett-Connor E, Faulkner KG, Wehren LE, Abbott TA, et al. Prediction of fracture risk in postmenopausal white women with peripheral bone densitometry: evidence from the National Osteoporosis Risk Assessment. Journal of Bone and Mineral Research 2002; 17: 2222-30.

29 Keegan TH, Gopalakrishnan G, Sidney S, Quesenberry CP Jr, Kelsey JL. Hormone replacement therapy and risk for foot, distal forearm, proximal humerus, and pelvis fractures. Osteoporosis International 2003; 14: 469-75.

30 Honkanen K, Honkanen R, Heikkinen L, Kroger H, Saarikoski S. Validity of self-reports of fractures in perimenopausal women. American Journal of Epidemiology 1999; 150: $511-16$.

31 Chen Z, Kooperberg C, Pettinger MB, Bassford T, Cauley JA, LaCroix AZ, et al. Validity of self-report for fractures among a multiethnic cohort of postmenopausal women: results from the Women's Health Initiative observational study and clinical trials. Menopause 2004; 11: 264-74.

32 Cooper C, Atkinson EJ, Hensrud DD, Wahner HW, O'Fallon WM, Riggs BL, et al. Dietary protein intake and bone mass in women. Calcified Tissue International 1996; 58: 320-5.

33 Rapuri PB, Gallagher JC, Haynatzka V. Protein intake: effects on bone mineral density and the rate of bone loss in elderly women. American Journal of Clinical Nutrition 2003; 77: 1517-25.

34 Kerstetter JE, O’Brien KO, Caseria DM, Wall DE, Insogna KL. The impact of dietary protein on calcium absorption and kinetic measures of bone turnover in women. Journal of Clinical Endocrinology and Metabolism 2005; 90: 26-31.

35 Hannan MT, Tucker KL, Dawson-Hughes B, Cupples LA, Felson DT, Kiel DP. Effect of dietary protein on bone loss in elderly men and women: the Framingham Osteoporosis Study. Journal of Bone and Mineral Research 2000; 15: 2504-12.

36 Sellmeyer DE, Stone KL, Sebastian A, Cummings SR. A high ratio of dietary animal to vegetable protein increases the rate of bone loss and the risk of fracture in postmenopausal women. Study of Osteoporotic Fractures Research Group. American Journal of Clinical Nutrition 2001; 73: 118-22.

37 Promislow JH, Goodman-Gruen D, Slymen DJ, BarrettConnor E. Protein consumption and bone mineral density in the elderly: the Rancho Bernardo Study. American Journal of Epidemiology 2002; 155: 636-44.

38 Devine A, Dick IM, Islam AF, Dhaliwal SS, Prince RL. Protein consumption is an important predictor of lower limb bone mass in elderly women. American Journal of Clinical Nutrition 2005; 81: 1423-8.

39 Dawson-Hughes B, Harris SS. Calcium intake influences the association of protein intake with rates of bone loss in elderly men and women. American Journal of Clinical Nutrition 2002; 75: 773-9.

40 Munger RG, Cerhan JR, Chiu BC. Prospective study of dietary protein intake and risk of hip fracture in postmenopausal women. American Journal of Clinical Nutrition 1999; 69: 147-52.

41 Barzel U, Massey LK. Excess dietary protein can adversely affect bone. Journal of Nutrition 1998; 128: 1051-3.

42 Schurch MA, Rizzoli R, Slosman D, Vadas L, Vergnaud P, Bonjour JP. Protein supplements increase serum insulin-like growth factor-I levels and attenuate proximal femur bone loss in patients with recent hip fracture. A randomized, double-blind, placebo-controlled trial. Annals of Internal Medicine 1998; 128: 801-9.

43 Burns L, Ashwell M, Berry J, Bolton-Smith C, Cassidy A, Dunnigan $\mathrm{M}$, et al. UK food standards agency optimal nutrition status workshop: environmental factors that affect bone health throughout life. British Journal of Nutrition 2003; 89: 835-40.

44 Bell J, Whiting SJ. Elderly women need dietary protein to maintain bone mass. Nutrition Reviews 2002; 60: 337-41.

45 Massey LK. Dietary animal and plant protein and human bone health: a whole foods approach. Journal of Nutrition 2003; 133: 862S-5S. 